\title{
Transient Hypothyroidism after Radioiodine for Graves' Disease: Challenges in Interpreting Thyroid Function Tests
}

\author{
Michael T. Sheehan, MD and Suhail A.R. Doi, MBBS, FRCP, PhD
}

\begin{abstract}
Graves' disease is the most common cause of hyperthyroidism and is often managed with radioactive iodine (RAI) therapy. With current dosing schemes, the vast majority of patients develop permanent post-RAI hypothyroidism and are placed on life-long levothyroxine therapy. This hypothyroidism typically occurs within the first 3 to 6 months after RAI therapy is administered. Indeed, patients are typically told to expect life-long thyroid hormone replacement therapy to be required within this timeframe and many providers expect this post-RAI hypothyroidism to be complete and permanent. There is, however, a small subset of patients in whom a transient post-RAl hypothyroidism develops which, initially, presents exactly as the typical permanent hypothyroidism. In some cases the transient hypothyroidism leads to a period of euthyroidism of variable duration eventually progressing to permanent hypothyroidism. In others, persistent hyperthyroidism requires a second dose of RAl. Failure to appreciate and recognize the possibility of transient post-RAl hypothyroidism can delay optimal and appropriate treatment of the patient. We herein describe five cases of transient post-RAI hypothyroidism which highlight this unusual sequence of events. Increased awareness of this possible outcome after RAI for Graves' disease will help in the timely management of patients.
\end{abstract}

Keywords: Graves disease; Radioiodine therapy; Hypothyroidism; Thyroid hormones; Treatment outcome

$\Lambda$ lthough not nearly as common as hypothyroidism, the overall prevalence of hyperthyroidism is still substantial at approximately $0.2 \%$, and in women the prevalence ranges between $0.5 \%$ and $2 \% .{ }^{1}$ The vast majority of the time Graves' disease is the underlying etiology, representing $60 \%$ to $80 \%$ of cases. $^{2}$ For decades the management options for Graves' disease have remained unchanged, consisting of either anti-thyroid drugs (ATD), radioactive iodine (RAI), or surgery. Though surgery has continued to be the least commonly employed management option, the proportion of patients managed with ATD or RAI varies by country. ${ }^{3}$ Additionally, there appears to be a trend toward less frequent use of RAI in both North America and Europe based on surveys of endocrinologists ${ }^{3}$ and ATD prescription trends. ${ }^{4}$ Despite these changing trends, RAI remains the most commonly employed treatment of Graves' disease in the United States.
With currently employed dosing regimens, hypothyroidism is the most common outcome after RAI therapy for Graves' disease, occurring in up to $80 \%$ of patients, the vast majority within the first 6 months. ${ }^{5}$ This is in contrast with the typical outcome of RAI therapy in the treatment of autonomously functioning thyroid nodular disease in which many patients will become and remain euthyroid after treatment. Though most patients with Graves' disease develop permanent postRAI hypothyroidism, there is a small subset ( $2 \%$ to $5 \%$ ) in whom the hypothyroidism is transient, which can confound the typically straightforward management of hypothyroidism. 5,6 Though the possibility of post-RAI transient hypothyroidism has been described in several older reports ${ }^{7-9}$ and a recent comprehensive review, ${ }^{6}$ it is not widely appreciated. Furthermore, it can sometimes be difficult to distinguish transient from permanent post-RAI hypothyroidism. Lastly, transient post-RAI hypothyroidism can, on recovery, be
Correspondence to: Michael T. Sheehan, MD, Marshfield Clinic Weston Center, Department of Endocrinology, 350I Cranberry Boulevard,Weston, WI 54476,

Tel: (7I5) 393-1366, Email: sheehan.michael@marshfieldclinic.org

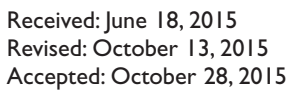


followed by either euthyroidism and eventual progression to permanent hypothyroidism without further therapy or persistent hyperthyroidism requiring a second dose of RAI therapy or anti-thyroid medication. ${ }^{6}$

We herein present five cases of transient post-RAI hypothyroidism highlighting the two possible eventual outcomes. In each case an unusual or unexpected pattern of laboratory data occurred after the initiation of levothyroxine therapy for post-RAI hypothyroidism. In four of these cases this occurred very shortly after replacement therapy was initiated, perhaps making it a bit more recognizable, but in one case the transient nature of hypothyroidism did not reveal itself for over a year. These cases highlight the importance of remaining aware of the possibility of the usual or even protracted transient post-RAI hypothyroidism, so that timely, appropriate management of the patient can occur.

\section{Case I}

A 42-year-old woman presented elsewhere with symptoms of tremors, palpitations, heat intolerance, and sleep disturbance in January 2000. At presentation, her physical examination was not well documented in the outside records. Her thyroid stimulating hormone (TSH) was $<0.01 \mathrm{mIU} / \mathrm{mL}$ (normal: 0.40-5.70), and a 24-hour radioactive iodine uptake (RAIU) was dramatically elevated at $89.2 \%$, indicative of Graves' disease. She received $7 \mathrm{mCi}(259 \mathrm{MBq})$ of I-131 for treatment in February. Three months later, she was subjectively and biochemically hypothyroid with a TSH of $14.29 \mathrm{mIU} / \mathrm{mL}$ and a free $\mathrm{T} 4$ of $<0.5 \mathrm{ng} / \mathrm{dL}$ (normal: 0.8-1.8). levothyroxine therapy was begun, and after several minor dose alterations, a stable dose of $0.1 \mathrm{mg}$ daily $(1.5 \mathrm{mcg} / \mathrm{kg} /$ day $)$ was achieved. In September 2001, 15 months later, during an evaluation for abdominal pain, her TSH was suppressed to $<0.01 \mathrm{mIU} / \mathrm{mL}$ with a free T4 elevated to $1.9 \mathrm{ng} / \mathrm{dL}$ on the same dose. Over the course of 4 months her thyroid hormone was decreased and eventually withdrawn, as her TSH remained undetectably low. Six weeks after thyroid hormone withdrawal, her TSH was $0.02 \mathrm{mIU} / \mathrm{mL}$ with normal levels of free T4 and free T3. A 4-hour RAIU was low normal at $7.9 \%$. She was referred to endocrinology. She denied taking excessive doses of thyroid hormone, and there were no alterations in other medications. As she was clinically well, she was followed without further intervention. Her TSH normalized 4 weeks later in March 2002. She remained well clinically with a normal TSH for 9 months off thyroid hormone until December 2002 when she presented with increasing fatigue of several weeks duration. Her TSH was $10.0 \mathrm{mIU} / \mathrm{mL}$ and free T4 $0.6 \mathrm{ng} / \mathrm{dL}$ (normal: 0.7-1.9). levothyroxine was restarted at $0.075 \mathrm{mg}$ daily, which remained stable as of the patient's last contact in 2005 .

\section{Case 2}

A 27-year-old man presented with severe Graves' hyperthyroidism in November 2006. Over the course of 4 months he had lost 30 pounds in weight and complained of anxiety, tremors, increased frequency of bowel movements, and sleep disturbance. On examination he was tachycardic with a heart rate of 120 beats per minute, had a fine bilateral upper extremity tremor, and a diffusely enlarged, nontender thyroid. Initial evaluation was as follows: TSH $<0.05 \mathrm{mIU} /$ mL (normal: 0.35-4.50), free T3 $29.4 \mathrm{pg} / \mathrm{mL}$ (normal: 2.14.1), free T4 $4.9 \mathrm{ng} / \mathrm{dL}$ (normal: 0.6-1.2), and 24-hour RAIU $84.1 \%$. He preferred to initiate therapy with methimizole; but after 4 months of persistent hyperthyroidism, he was treated with $16.2 \mathrm{mCi}$ (599 MBq) I-131 after holding methimazole for 5 days (TSH $<0.05 \mathrm{mIU} / \mathrm{mL}$, free T3 $18.6 \mathrm{pg} / \mathrm{mL}$ and free T4 4.6 ng/dL). Four months later, in July 2007, hypothyroidism was confirmed with TSH $45.89 \mathrm{mIU} / \mathrm{mL}$ and free T4 $0.1 \mathrm{ng} /$ dL. He had been off methimazole since I-131 therapy. He was treated with levothyroxine $0.1 \mathrm{mg}$ daily $(1.1 \mathrm{mcg} / \mathrm{kg} / \mathrm{day})$, but within 6 weeks the dose had to be tapered and eventually discontinued due to a persistently suppressed TSH. In December 2007, off levothyroxine for 8 weeks, he had the following laboratory data: TSH $<0.05 \mathrm{mIU} / \mathrm{mL}$, free T3 6.6 $\mathrm{pg} / \mathrm{mL}$, free T4 $2.0 \mathrm{ng} / \mathrm{dL}$, and $\mathrm{TSH}$ receptor antibody 52 (normal: <16). Further evaluation and treatment had to be delayed briefly, but RAIU in February 2008 was $49.2 \%$ at 24 hours, and he was treated with a second dose of I-131 at 27.6 mCi (1021 MBq). Within 6 weeks, in late March 2008, he was hypothyroid again (TSH $5.33 \mathrm{mIU} / \mathrm{mL}$ and free T4 $0.1 \mathrm{ng} /$ $\mathrm{dL}$ ), and levothyroxine $0.1 \mathrm{mg}$ daily was reinitiated. By July 2008, his TSH was normal on $0.175 \mathrm{mg}$ daily, and at last contact in December 2013 his TSH remained normal.

\section{Case 3}

A 46-year-old man presented in May 2007 with an 8-week history of tremor, palpitations, heat intolerance, sleep disturbance, and fatigue. He had lost 20 pounds in weight. Examination revealed mild tachycardia at 102 beats per minute and a fine bilateral upper extremity tremor. His thyroid was firm and asymmetric without palpable nodule. His TSH was suppressed at $0.04 \mathrm{mIU} / \mathrm{mL}$ (normal: $0.35-4.50$ ) with elevation of free T3 and free T4 at $12.1 \mathrm{pg} / \mathrm{mL}$ and 4.2 $\mathrm{ng} / \mathrm{dL}$, respectively (normal: free T3 2.1-4.1 pg/mL and free T4 0.6-1.2). His 4-hour RAIU was mildly elevated at $22.6 \%$ with an asymmetric but bilaterally diffuse pattern. Thyroid ultrasound revealed a slightly asymmetric thyroid that showed mild, diffuse heterogeneity but no nodules. He received 25.8 $\mathrm{mCi}(955 \mathrm{MBq})$ of I-131 for the treatment of his Graves' disease. Three months later he developed hypothyroidism (TSH $23.87 \mathrm{mIU} / \mathrm{mL}$ and free T4 $<0.1 \mathrm{ng} / \mathrm{dL}$ ) and began levothyroxine at $0.150 \mathrm{mg}$ daily $(1.5 \mathrm{mcg} / \mathrm{kg} / \mathrm{day})$. Six weeks later his TSH was suppressed at $<0.05 \mathrm{mIU} / \mathrm{mL}$, and his dose was tapered over time. By March 2008 (9 months after post-I131 hypothyroidism had developed), he was still hyperthyroid on just $0.05 \mathrm{mg}$ levothyroxine daily: $\mathrm{TSH}<0.05$ $\mathrm{mIU} / \mathrm{mL}$, free T3 $3.8 \mathrm{pg} / \mathrm{mL}$ and free T4 $1.5 \mathrm{ng} / \mathrm{dL}$. Graves' antibodies were positive with a TSH receptor antibody at 44 (normal: <16). Levothyroxine was discontinued, and eventually his thyroid function tests normalized 5 months later without further treatment (TSH $0.38 \mathrm{mIU} / \mathrm{mL}$ and free T4 $0.6 \mathrm{ng} / \mathrm{dL}$ ). In November 2008, his TSH remained normal at $2.69 \mathrm{mIU} / \mathrm{mL}$. He was lost to follow-up until July 2010, when his TSH had risen to $30.14 \mathrm{mIU} / \mathrm{mL}$. Levothyroxine 
was reinitiated at $0.088 \mathrm{mg}$ daily, and the patient's TSH remained normal on that dose as of October 2013.

\section{Case 4}

In October 2001, a 44-year-old woman was incidentally found to have a goiter on a magnetic resonance imaging scan of her neck and shoulder performed for evaluation of a rotator cuff injury. Thyroid function tests revealed hyperthyroidism (TSH $<0.03 \mathrm{mIU} / \mathrm{mL}$ [normal: $0.50-5.5$ ] and free T4 $4.6 \mathrm{ng} /$ $\mathrm{dL}$ [normal: 0.8-1.9]), and a thyroid uptake and scan revealed a homogenously elevated uptake of $75 \%$ at 24 hours consistent with Graves' disease. She denied symptoms of thyrotoxicosis. On examination, however, she was tachycardic, had mild signs of Graves' eye disease, a small, firm symmetric goiter, fine upper extremity tremor, and hyperreflexia. She received $12.5 \mathrm{mCi}(463 \mathrm{MBq})$ of I-131 for treatment. Three months after RAI therapy she was clinically hypothyroid, complaining of significant fatigue and having gained $9 \mathrm{~kg}$. Her TSH was $<0.03 \mathrm{mIU} / \mathrm{mL}$ with a low free T4 of $0.6 \mathrm{ng} / \mathrm{dL}$. She was felt to indeed be hypothyroid, and her TSH was deemed to be lagging behind in its predicted rise related to her previous hyperthyroidism. She was started on levothyroxine $0.125 \mathrm{mg}$ daily $(1.1 \mathrm{mcg} / \mathrm{kg} /$ day $)$. Six weeks later she felt improved but, as her TSH was $<0.03 \mathrm{mIU} / \mathrm{mL}$, her dose was decreased. Over the next 6 months her dose was tapered and eventually discontinued due to continual suppression of her TSH. Six weeks after discontinuing levothyroxine, her RAIU was 56\% at 24 hours, indicative of persistent Graves' disease. Her TSH was $<0.03 \mathrm{mIU} / \mathrm{mL}$ with a free T4 of $2.2 \mathrm{ng} / \mathrm{dL}$ (normal: 0.7 1.7). She was scheduled to receive a second dose of radioactive iodine but never followed through with treatment. She remained mildly hyperthyroid until June 2005, when her TSH normalized spontaneously (nearly 3.5 years off levothyroxine). Almost 6 and 1/2 years off levothyroxine, in April 2008, her TSH remained normal at 2.92. She eventually developed hypothyroidism in November 2009 (more than 8 years after I-131 therapy), with a mildly elevated TSH of 9.66 $\mathrm{mIU} / \mathrm{mL}$, and was started on levothyroxine. After several minor dose adjustments, she has been maintained on 0.112 mg daily with a normal TSH as of November 2014.

\section{Case 5}

In September 2007, a 31-year-old woman presented with several months of symptoms consistent with hyperthyroidism including tremor, anxiety, sleep disturbance, and palpitations. Physical examination revealed a heart rate of 112 beats per minute and a fine bilateral upper extremity tremor. She had a firm, diffusely enlarged thyroid gland with a soft bruit. Her laboratory data revealed a TSH of $<0.05 \mathrm{mIU} / \mathrm{mL}$ (normal: $0.35-4.50$ ), a free T3 of $22.6 \mathrm{pg} / \mathrm{mL}$ (normal: $2.1-4.1$ ), and a free T4 of $4.7 \mathrm{ng} / \mathrm{dL}$ (normal: 0.6-1.9). Her thyroid uptake was elevated at $62 \%$ in a diffuse pattern, confirming Graves' disease. It was recommended that RAI therapy be pursued, but she preferred to utilize anti-thyroid drug therapy, so propylthiouracil (PTU) $100 \mathrm{mg}$ three times daily was begun. Despite the inability to completely normalize her thyroid function tests, the patient refused to undergo I-131 therapy.
She remained on PTU, following up with her primary provider until she was referred back to endocrinology in January 2010. At that time she was willing to undergo RAI therapy, and received a $22.6 \mathrm{mCi}(836 \mathrm{MBq})$ dose in May 2010. She had been off PTU for 8 weeks prior to RAI therapy. Ten weeks later she was biochemically hypothyroid with a TSH 0.13 $\mathrm{mIU} / \mathrm{mL}$ and a free $\mathrm{T} 4$ of $0.4 \mathrm{ng} / \mathrm{dL}$, and levothyroxine was begun at $0.1 \mathrm{mg}$ daily $(1.6 \mathrm{mcg} / \mathrm{kg} /$ day $)$. Within 2 months, at her first recheck, her TSH was suppressed at $0.02 \mathrm{mIU} / \mathrm{mL}$, and over the next 2-3 months her dose was tapered and eventually discontinued. In January 2011, 6 weeks off levothyroxine, she had the following laboratory data: TSH $<0.05 \mathrm{mIU} / \mathrm{mL}$, free T3 $3.6 \mathrm{pg} / \mathrm{mL}$, free T4 $0.9 \mathrm{ng} / \mathrm{dL}$ and TSH receptor antibody 19 (normal: <16). She remained mildly hyperthyroid in March 2011 but eventually redeveloped hypothyroidism in November 2011 (18 months after I-131 therapy) with a TSH of $10.70 \mathrm{mIU} / \mathrm{mL}$. Levothyroxine was reinitiated, and after several dose adjustments, she has remained euthyroid on $0.1 \mathrm{mg}$ daily as of July 2014 with a $\mathrm{TSH}$ of $2.75 \mathrm{mIU} / \mathrm{mL}$.

\section{Discussion}

Transient hypothyroidism after RAI therapy is of two types: ${ }^{6} \mathrm{a}$ hibernation-like condition (prolonged thyroid stunning) where ionizing radiation in sub-lethal doses temporarily impairs the thyroid function with elevated TSH and low T4, and transient central hypothyroidism with both low TSH and low or low normal T4. In both instances, hypothyroidism occurs between 2 to 3 months after radioiodine therapy, lasts between 2 to 4 weeks, and on resolution reveals the true state, which could either be euthyroidism or persistent hyperthyroidism. Despite several papers having been written about transient hypothyroidism following RAI therapy ${ }^{7-9}$ and brief mention in reviews of Graves' disease, ${ }^{2}$ the potential for this phenomenon to occur may not be widely appreciated, as demonstrated in these cases. In the case of the 'prolonged stunning' leading to transient hypothyroidism, studies have shown that there is a 'valley' pattern most frequently seen after RAI therapy, and it is when the bottom of this valley enters the hypothyroid range that transient hypothyroidism ensues (Figure 1). ${ }^{10}$ This bottom appears after 3 months of therapy and may represent mainly an impaired function of thyroid cells that received the direct and maximum effect of I-131, after which functional recovery of impaired but surviving follicular cells occurs. ${ }^{10}$ This form of stunning is different from that seen immediately after RAI administration where iodide transport is reduced, ${ }^{11}$ or from the effect of propylthiouracil on thyroidal uptake of RAI when used within 2 weeks of administration of RAI. ${ }^{12,13}$ Both of the latter are concerns regarding the effectiveness of RAI subsequently, rather than on transient hypothyroidism at 3 months, although this does not preclude a flow on effect too.

The incidence of transient hypothyroidism due to prolonged stunning after RAI therapy (seen in cases 1 to 3 above and summarized in Table 1) is highly variable and seems to correlate with the dosing scheme utilized. As higher dosing methods have been employed to increase the success rate of 
RAI therapy, the rate of transient hypothyroidism has diminished. We employ what would be considered a high dose method by attempting to deliver an average ablative radiation absorbed dose of about 200 to 250 Gy to the thyroid. We empirically equate this to a delivered activity of $10 \mathrm{mCi}$ (370 MEq) to the thyroid gland and, thus, correct the administered activity for RAI uptake. This dosage scheme may deliver an increased radiation absorbed dose to smaller goiters and, for example, at our institution, a patient with an RAI uptake of $50 \%$ would receive approximately a $20 \mathrm{mCi}$ $(740 \mathrm{mBq})$ dose of I-131. Gómez et $\mathrm{al}^{7}$ reported a $17.5 \%$ rate of transient hypothyroidism in 126 patients with Graves' disease treated with a mean I-131 dose of $6.8 \mathrm{mCi}(252$ $\mathrm{MBq}$ ). Similarly, the same group reported an $11.3 \%$ rate of transient hypothyroidism in 333 patients treated with low dose I-131 (mean $6.6 \mathrm{mCi}$ or $244 \mathrm{MBq}$ ) versus $0 \%$ in 22 patients treated with a higher dose (mean $12.8 \mathrm{mCi}$ or 474 $\mathrm{MBq}){ }^{8}$ More recently, Alexander and Larson ${ }^{5}$ reported on 261 patients treated with a high dose regimen (mean 14.6 $\mathrm{mCi}$ or $540 \mathrm{MBq}$ ), showing just a $1.9 \%$ rate of transient hypothyroidism. Some studies have not shown any prognostic factors to reliably predict transient hypothyroidism due to stunning, ${ }^{7,8}$ while one suggests younger age, larger goiters, and pretreatment with PTU to be predictive. Also, failure of I-131 treatment may be more common in men versus women. ${ }^{14,15}$ Note is made that two of these three cases of thyroid stunning were male, and we may speculate perhaps this indicates a preponderance of transient hypothyroidism in men. Case 2 did have anti-thyroid drug pre-treatment, though pre-treatment goiter size was not commented on in the cases. Cases 1 and 2 did have a very high RAIU, which is predictive of treatment failure ${ }^{5}$ but not transient hypothyroidism due to stunning. Interestingly, case 1 received what would be considered low dose therapy (and may thus have been at risk to develop transient hypothyroidism due to stunning), while cases 2 and 3 received higher doses. Thus, transient hypothyroidism due to stunning after RAI therapy is difficult to predict and should be thought of when an unusual pattern of events follows the development of hypothyroidism. The unexpected development of a suppressed TSH on a stable dose of levothyroxine and the failure to achieve a stable dose because of a continually suppressed TSH were such clues in cases 1 through 3 .

Case 1 deserves further discussion, as most patients with transient hypothyroidism following RAI therapy progress within weeks to their next definitive status, and indeed, this is the pattern in $77 \%$ to $85 \%$ of transient hypothyroid cases. ${ }^{7,8}$ It seems, therefore, that the pattern of protracted transient hypothyroidism seen in case 1 is unusual. This begs the question of what precisely might have been the cause of this prolonged period of "transient" hypothyroidism. While it may

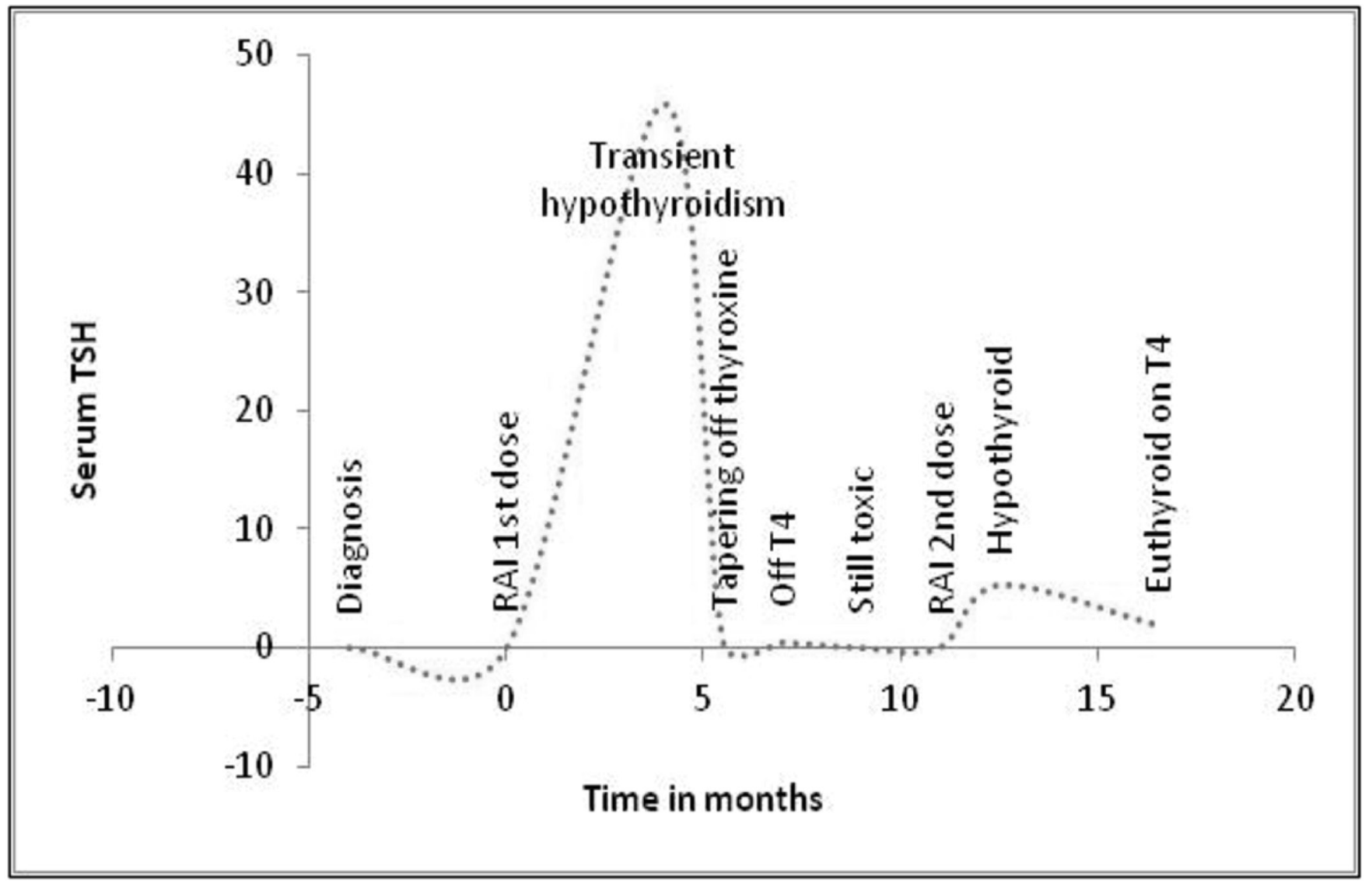

Figure 1. A typical sequence of transient hypothyroidism post-radioactive iodine (based on case 2). 


\begin{tabular}{|c|c|c|}
\hline Case & Characteristics & Sequence of thyroid status events \\
\hline \multirow[t]{5}{*}{1} & Female, 42 years & - $7 \mathrm{mCi}$ \\
\hline & RAI uptake: $89.2 \%$ & - $\quad$ transient hypothyroidism (protracted; $3^{\text {rd }}$ to $15^{\text {th }}$ month) \\
\hline & ATD pretreatment: No & - recurrent hyperthyroidism ( $15^{\text {th }}$ month to $21^{\text {st }}$ month) \\
\hline & & - $\quad$ euthyroidism ( $21^{\text {th }}$ month to $30^{\text {th }}$ month) \\
\hline & & - $\quad$ permanent hypothyroidism thereafter \\
\hline \multirow[t]{5}{*}{2} & Male, 27 years & - $\quad 16.2 \mathrm{mCi}$ \\
\hline & RAl uptake: $84.1 \%$ & - $\quad$ transient hypothyroidism (short lived) \\
\hline & ATD pretreatment: Yes & - $\quad$ persistent hyperthyroidism ( $4^{\text {th }}$ month to $11^{\text {th }}$ month) \\
\hline & & - $\quad 27.6 \mathrm{mCi}-2^{\text {nd }}$ dose \\
\hline & & - $\quad$ permanent hypothyroidism thereafter \\
\hline \multirow[t]{5}{*}{3} & Male, 46 years & - $\quad 25.8 \mathrm{mCi}$ \\
\hline & RAI uptake: $22.6 \%$ & - $\quad$ transient hypothyroidism (short lived) \\
\hline & ATD pretreatment: No & - $\quad$ persistent hyperthyroidism ( $3^{\text {rd }}$ month to $13^{\text {th }}$ month) \\
\hline & & - $\quad$ euthyroidism ( $13^{\text {th }}$ month to $37^{\text {th }}$ month) \\
\hline & & - $\quad$ permanent hypothyroidism thereafter \\
\hline \multirow[t]{5}{*}{4} & Female, 44 years & - $\quad 12.5 \mathrm{mCi}$ \\
\hline & RAI uptake: $75.0 \%$ & - $\quad$ transient hypothyroidism (short lived) \\
\hline & ATD pretreatment: No & - $\quad$ persistent hyperthyroidism (6 $6^{\text {th }}$ week to 3.5 years) \\
\hline & & - $\quad$ euthyroidism $\left(3.5-8^{\text {th }}\right.$ years $)$ \\
\hline & & - $\quad$ permanent hypothyroidism thereafter \\
\hline \multirow[t]{5}{*}{5} & Female, 31 years & - $\quad 22.6 \mathrm{mCi}$ \\
\hline & RAI uptake: $62.0 \%$ & - $\quad$ transient hypothyroidism (short lived) \\
\hline & ATD pretreatment: Yes & - $\quad$ persistent hyperthyroidism ( $2^{\text {nd }}$ month to $18^{\text {th }}$ month) \\
\hline & & - $\quad$ euthyroidism (short lived) \\
\hline & & - $\quad$ permanent hypothyroidism thereafter \\
\hline
\end{tabular}

ATD, anti-thyroid drugs; RAI, radioactive iodine

have started off as thyroid stunning, the protracted course might be related to TSH receptor antibody (TSHrAb) fluctuations. It seems plausible that the low dose of I-131 used to treat case 1 left some residual functioning thyroid tissue, despite her biochemical and symptomatic hypothyroidism. This tissue would then be influenced by any fluctuation in TSHrAb levels that might subsequently occur, thus leading to 15 months of hypothyroidism that subsequently recovered. The potential for thyroid antibodies to play such a role has been described by Yoshida et $\mathrm{al}^{16}$ who reported on fluctuating levels of TSI and TBII after RAI therapy, which had some correlation to fluctuating thyroid function. TSH receptor antibody levels were not drawn in this patient, so this possibility cannot be proven though, again, it certainly seems plausible. This patient then progressed to euthyroidism after resolution of the protracted but transient hypothyroid state. Such euthyroidism after radioiodine depends on the dose administered, with lower doses tending to allow prolonged periods of euthyroidism as opposed to higher doses where permanent hypothyroidism ensues quickly. This dosedependent effect of radioiodine is due to a direct cellular toxicity of radiation, but once euthyroidism ensues, hypothyroidism is inevitable because of the persistent effect of radioiodine due to continuing mitotic cell death, which is independent of dose. ${ }^{17}$ Thus, the lower dose in case 1 rendered her euthyroid for a prolonged period before permanent hypothyroidism ensued, but it should be kept in mind that for her, permanent future hypothyroidism was inevitable at this point, and all such patients must have this anticipated so that once this occurs, replacement is promptly begun.

Cases 4 and 5 (described above and summarized in Table 1) demonstrate transient central hypothyroidism, which on recovery revealed failure of radioiodine treatment, suggesting persistent as opposed to recurrent hyperthyroidism. Central hypothyroidism usually occurs a mean of 2 months after radioiodine therapy, lasts an average of 25 days, ${ }^{18}$ and has been thought to represent the recovery period for pituitary TSH secretion following a lowering of T4 by radioiodine (or other forms of therapy for Graves' disease). It should be kept in mind that the presence of a central hypothyroid phase is very common $^{7,8}$ and does not predict treatment success or failure. 
The initially suppressed TSH in cases 4 and 5 did not, therefore, indicate persistent hyperthyroidism at 3 months, but rather a delay in pituitary responsiveness after acute lowering of T4 levels post-radioiodine. The subsequent hyperthyroidism in both cases begs the question of whether this T4 lowering is also a consequence of thyroid stunning. It could very well be, and if so, then it may be that transient central hypothyroidism only occurs when there is early transient or permanent hypothyroidism. In cases 4 and 5, there must have been a short-lived period of thyroid stunning, but after recovery their subsequent clinical courses were persistent hyperthyroidism. Case 4 had a very prolonged period of recurrent hyperthyroidism (3.5 years) followed by an equally prolonged euthyroid state (approximately 4 years) before finally developing permanent post I-131 hypothyroidism. This is understandable, as the radioiodine dose given was on the lower side $(12.5 \mathrm{mCi}$ or $463 \mathrm{MBq})$. Case 5, however, had a shorter-lived (16 months) recurrent hyperthyroid phase before transitioning to permanent hypothyroidism, given that the I-131 dose was higher (22.6 $\mathrm{mCi}$ or $836 \mathrm{MBq})$. Most patients receiving $15 \mathrm{mCi}$ (555 $\mathrm{MBq}$ ) develop permanent hypothyroidism in 6 to 9 months, ${ }^{17}$ so this pattern is unusual. That each patient eventually redeveloped hypothyroidism is a testament to the persistent effect of the radioiodine dose, and thus, if we wait long enough, all patients will develop permanent thyroid failure. ${ }^{17}$

In summary, while the vast majority of patients treated with radioiodine for Graves' disease follow a straightforward course of post I-131 hypothyroidism enjoying a stable, longterm follow-up on levothyroxine replacement therapy, a small subset of patients follow a more unusual course marked by transient hypothyroidism, and this can adversely impact decision making. The underlying mechanism of transient post I-131 hypothyroidism is of two types - thyroid stunning and transient central hypothyroidism - and in many cases central hypothyroidism can occur due to acute lowering of serum T4 due to stunning. The underlying mechanism may not be as important as the simple awareness of the possibility and early recognition of the transient nature of the hypothyroidism. In the vast majority of cases, this transient nature of the hypothyroidism is not recognized and then manifests itself shortly after levothyroxine therapy is initiated, usually demonstrating a fully suppressed TSH at the first laboratory assessment after replacement therapy is begun. More uncommonly, the transient nature of post-RAI hypothyroidism may not manifest until much later. Thus, increased awareness of this usual entity is especially warranted in patients with unexpected laboratory data shortly after initiation of levothyroxine replacement therapy and continued attentiveness by both the patient and provider should be maintained long-term.

\section{References}

1. Vanderpump MPJ. The epidemiology of thyroid disease. Br Med Bull. 2011;99(1):39-51.

2. Weetman AP. Graves' Disease. N Engl J. Med 2000;343 (17):1236-1248.
3. Burch HB, Burman KD, Cooper DS. A 2011 survey of clinical practice patterns in the management of Graves' disease. J Clin Endocrinol Metab. 2012;97(12):4549-4558.

4. Emiliano AB, Governale L, Parks M, Cooper DS. Shifts in propylthiouracil and methimazole prescribing practices: antithyroid drug use in the United States from 1991 to 2008. J Clin Endocrinol Metab. 2010;95(5):2227-2233.

5. Alexander EK, Larsen PR. High dose of (131)I therapy for the treatment of hyperthyroidism caused by Graves' disease. J Clin Endocrinol Metab. 2002;87(3):1073-1077.

6. Bonnema SJ, Hegedüs L. Radioiodine therapy in benign thyroid diseases: effects, side effects, and factors affecting therapeutic outcome. Endocr Rev. 2012;33(6):920-980.

7. Gómez JM, Virgili N, Soler J, Fernández M, Montaña E. Transient hypothyroidism after iodine-131 treatment of Graves' disease. Thyroidology. 1989;1(3):149-152.

8. Gómez N, Gómez JM, Orti A, et al. Transient hypothyroidism after iodine-131 therapy for Grave's disease. J Nucl Med. 1995;36(9):1539-1542.

9. Aizawa Y, Yoshida K, Kaise N, et al. The development of transient hypothyroidism after iodine-131 treatment in hyperthyroid patients with Graves' disease: prevalence, mechanism and prognosis. Horumon To Rinsho. 1997;46(1):1-5.

10. Nakajo M, Tsuchimochi S, Tanabe H, Nakabeppu Y, Jinguji M. Three basic patterns of changes in serum thyroid hormone levels in Graves' disease during the one-year period after radioiodine therapy. Ann Nucl Med. 2005;19(4):297-308.

11. Medvedec M. Thyroid stunning in vivo and in vitro. Nucl Med Commun. 2005;26(8):731-735.

12. Shi GM, Xu Q, Zhu CY, Yang YL. Influence of propylthiouracil and methimazole pre-treatment on the outcome of iodine-131 therapy in hyperthyroid patients with Graves' disease. J Int Med Res. 2009;37(2):576-582.

13. Turton DB, Silverman ED, Shakir KMM. Time interval between the last dose of propylthiouracil and I-131 therapy influences cure rates in hyperthyroidism caused by Graves' disease. Clin Nucl Med. 1998;23(12):810-814.

14. Allahabadia A, Daykin J, Holder RL, Sheppard MC, Gough SC, Franklyn JA. Age and gender predict the outcome of treatment for Graves' hyperthyroidism. J Clin Endocrinol Metab. 2000;85(3):1038-1042.

15. Allahabadia A, Daykin J, Sheppard MC, Gough SC, Franklyn JA. Radioiodine treatment of hyperthyroidism-prognostic factors for outcome. J Clin Endocrinol Metab. 2001;86(8):3611-3617.

16. Yoshida K, Aizawa Y, Kaise N, et al. Role of thyroidstimulating blocking antibody in patients who developed hypothyroidism within one year after 131I treatment for Graves' disease. Horumon To Rinsho. 1998;48(1):17-22.

17. Doi SAR, Loutfi I, Al-Shoumer KAS. A mathematical model of optimized radioiodine-131 therapy of Graves' hyperthyroidism. BMC Nucl Med. 2001;1(1):1.

18. Uy HL, Reasner CA, Samuels MH. Pattern of recovery of the hypothalamic-pituitary-thyroid axis following radioactive iodine therapy in patients with Graves' disease. Am J Med. 1995;99(2):173-179.

\section{Author Affiliations}

Michael T. Sheehan, MD* and Suhail A.R. Doi, MBBS, FRCP, $P h D^{+}$

*Department of Endocrinology, Marshfield Clinic, Weston, WI, USA

Research School of Population Health, Australian National University, Acton, Canberra, Australia 